\title{
Complexity in economics and beyond: Review paper
}

\author{
Deniz Durmus* \\ Business and Economics Department, Sarajevo School of Science and Technology, Bosnia
}

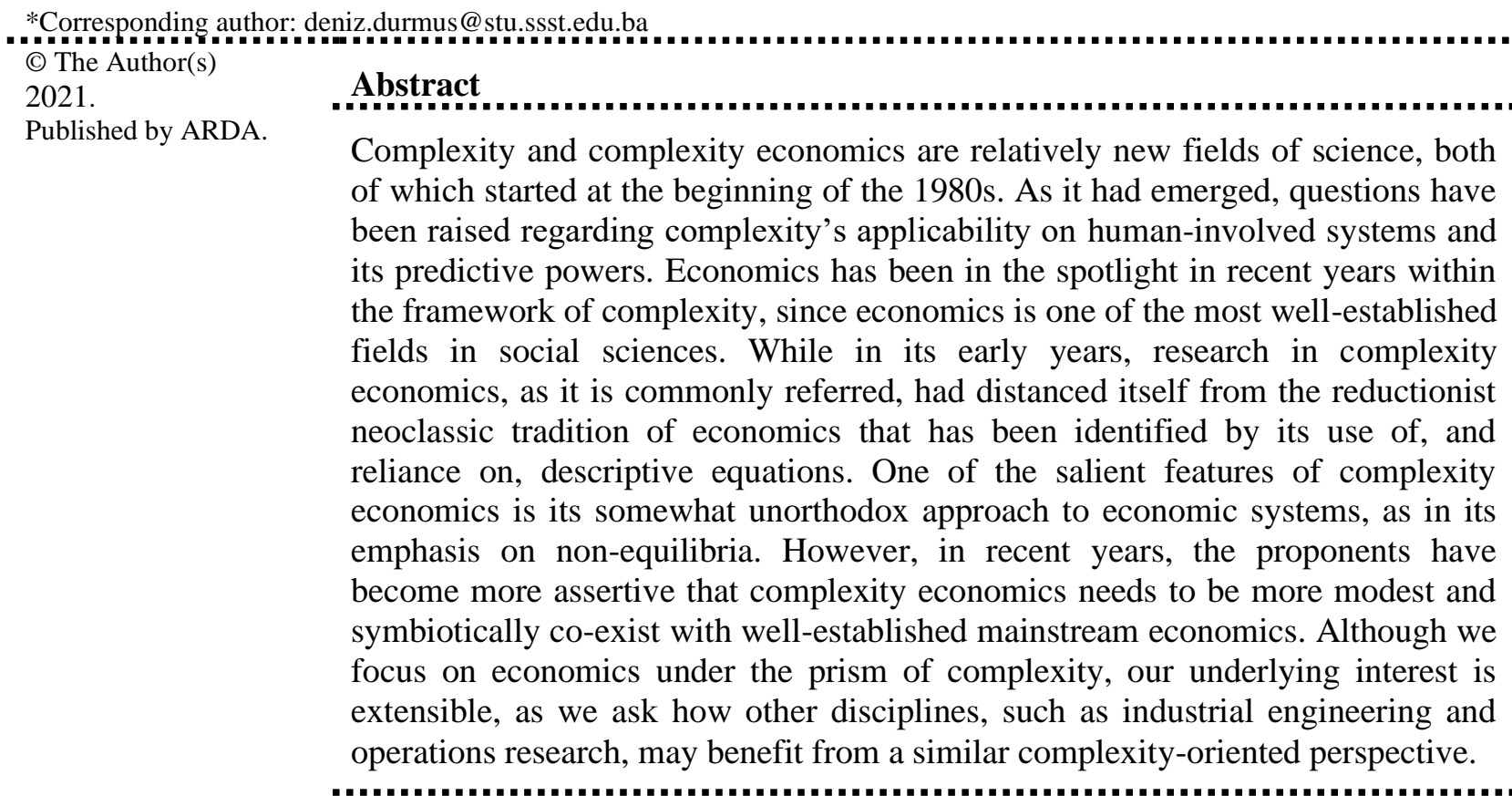

Keywords: Complexity, Complexity economics, Mainstream economics, Equation-based economics, Non-equilibrium

\section{Introduction}

It may be said that Complexity Economics is still in its embryonic developmental stages. So far, there is no universally agreed upon consensus as to what it is or is not. Neither its nor that of complexity in general has a well-accepted definition. Moreover, its applicability to real world problems is also similarly being debated. One might say that this is due to the interdisciplinary nature of the field. As such, it requires scholars to fully grasp some core ideas outside their respected fields of expertise. As an emerging field, there is still much to be discovered. As it is reported (see [1] and [2]), the topic lacks a "meta-theoretical foundation". We can deduce that complexity economics is a science in its establishment and growth, in a phase of pre-science. As such, much debate is philosophical in nature, where economists and complexity scientists seek a common ground and a methodological framework. The term "Complexity Economics" was coined by Brian W. Arthur, from the Santa Fe Institute (SFI), who led the Economics Program at SFI in the late 1980s. In its most general sense, complexity economics aims to solve problems consisting of complex systems in economics within the framework of complexity science. Farmer [3] differentiates complexity economics by comparing it to mainstream economics and econometrics. He urges economists to take a complexity-economics approach to the problems of economy:

This work is licensed under a Creative Commons Attribution License (https://creativecommons.org/licenses/by/4.0/ ) that allows others to share and adapt the material for any purpose (even commercially), in any medium with an acknowledgement of the work's authorship and initial publication in this journal. 
"The complex systems approach is intermediate between traditional economic theory and econometrics. Traditional economic theory is top-down, modeling decision making from first principles, and then testing against data later. By "first principles" I mean the requirement that theories have "economic content", i.e., that they derive behaviors from preferences. Econometrics, in contrast, takes a bottom up, data-driven, but fundamentally ad hoc approach. The complex systems approach sits in the middle, taking a bottom-up data-driven approach that differs from traditional econometrics by explicitly representing agents and institutions and modeling their interactions, without the requirement that everything be derived from fundamental principles" [3].

Complexity economics' point of view regards the constituents of economics as constantly evolving nonequilibrium structures [4]. However, this does not mean that equilibrium is not significant in economics, since "[they] are useful for situations in economics that are well-defined, rationalizable, and reasonably static" [4]. Arthur [4] also argues that this new approach stems from the change in science with the advancement of computers and computation. He states that "science and mathematics are shedding their certainties and embracing openness and procedural thinking, and there is no reason to expect that economics will differ in this regard". The approach of mathematics and the science of complexity distance itself from traditional Newtonian mechanics and solves problems with algorithms and algorithmic thinking [4]. Algorithmic thinking brings convenience to research, due to its flexibility and similarity to human language [1, p. 398].

There is also much criticism and skepticism towards complexity science and complexity economics. Some of this comes from Ref. [5], whose arguments provide a general overview to the criticism to the field. He and other critics reprehend complexity science for its attempt to solve everything, albeit its framework is still very vague. Although, complexity economics started off ambitiously in the 1980s, and until the beginning of 2000s, researchers of complexity economics distanced themselves from the field of orthodox economics (also called traditional economics or mainstream economics). However, as the field gained more popularity, and still lacking a meta-theory or a complete framework, it has become closer and more genial to mainstream economics, without losing its ambition for a novel understanding. In the last two decades, more and more have started to assert that mainstream economics, and specifically the neoclassical tradition, is already a wellestablished school of economics from which researchers of complexity economics needs to benefit.

This paper aims to explain complexity economics by providing the most fundamental and intrinsic features of complexity as it has been associated with economics to those who are interested in the field of complexity or economics. The literature that emerged since the beginning of complexity economics up to the 2010s seems to be rather strongly opinionated, which is reviewed in Sections 3 and 4. As an emerging applied field which often serves as an example of how complexity may be incorporated into well-established scientific domains, complexity economics attracts not only economists and complexity scientists, but a much wider audience. However, there seems to be a lack of papers that provide the central ideas of complexity economics. The review and related comments presented in this article; we aim to provide a remedy to this shortfall. As such, this review will be beneficial not only to complexity scientists and economists, but also to academicians from applied and natural sciences as well as to the general public.

In the next section Complexity and Complex Systems, we explain complexity science, which also highlights the features of complexity economics. The section after that, Complexity Economics: Santa Fe Institute, Where It All Started provides a historical overview of the Santa Fe Institute where complexity economics had started. That section sheds light on how complexity economics evolved throughout the years. Later, in the section Complexity Economics: Current Debates, we present the main discussions regarding complexity economics. Then we conclude the paper with our specific remarks.

\section{Complexity and complex systems}

Complexity science is relatively new to the scientific world. Accordingly, the general field as well as one of its specialization areas, namely complexity economics, lacks a well-accepted standard definition. Although the 
foundation of general systems stretches back to the 1940s, or even earlier with work on Bogdanov's tektology in 1922, the notion "complexity science" is coined in the 1980s [6].

Complexity deals with the area that is called the meso-layer. This property stems from the definition of the American mathematician and scientist Weaver [7], who partitions scientific problems into three categories: problems of simplicity, problems of disorganized complexity, and problems of organized complexity. Problems of the organized complexity is the domain of complexity science, and hence complexity economics.

The problems in the meso-layer, the problems of disorganized complexity as Weaver calls it, consists of variables that cannot be dealt with like case-study problems as in the problems of simplicity, nor can they be averageable as in problems of disorganized complexity. For example, while the motion of two objects falls into the problems of simplicity (described by only a few variables), the motion of gas atoms in a room (billions of variables) falls into the problems of disorganized complexity. In the latter, the behavior of one single variable is not predictable. However, the behavior of the whole system is predictable with the use of statics and statistical mechanics.

As the focus of this study, the problems of organized complexity, statistical methods fall short in explaining the behavior of complex system. This is due to the properties of emergence which complex systems possess. As mentioned, the term "complexity" has still not been well defined [8]. This is due to the fact that it covers a vast number of research domains such as economics, sociology, political science, biology, etc. Nonetheless, Mitchell [8] proposes a definition:

"A complex system [is] a system in which large networks of components with no central control and simple rules of operation give rise to complex collective behavior, sophisticated information processing, and adaptation via learning or evolution." [8].

By proposing a definition built on the common properties of complex systems, she suggests:

(a) The individuals (parts) of complex systems behave collectively. It is not possible to understand the behavior of the systems just by observing one or two individuals. Without having a leader or consciousness, the individuals work in coherence and form trends and behavior as a whole. While each agent (individual, institution, banks, government, etc.) follows a simple rule, their collective behavior, and the patterns of their behavior are hard to predict. American economist Thomas Schelling refers to this as "micromotives, macrobehavior" meaning that micromotives of agents give rise to macrobehavior of the society [9].

(b) Complex systems use information and signals of their internal and external environments. This is also known as the "the whole is greater than the sum of its parts" - a phrase coined by Aristotle. This phrase also suggests that to understand the whole, analyzing and understanding only the behavior of the agents of a system is not sufficient. Also, relations between the agents are crucial due to the interdependence between agents [10].

(c) Complex systems adapt. The behavior of agents iterates, they reform their strategies and behavior, they learn and evolve. This notion is sometimes called emergence.

Grabner [1] also adds that the parts of complex systems are heterogeneous and the emergence "may feed back to the parts on lower ontological levels". While Arthur [11] states similar properties of complex systems, he also argues that "complex systems are systems in process, systems that constantly evolve and unfold over time". Nonlinearity in complex systems, as well as in complexity economics, is another common property that the scholars name [12], [13], [14]. Parallel to this view Fontana [15] affirms that while all complex systems are nonlinear, not all nonlinear systems are complex.

Castellani [16] maps out all fields relevant to complexity science and shows that the roots of complexity science are based on dynamical systems, systems theory, complex systems theory, cybernetics, and cognitive 
science. Its application is commonly accepted in the fields such as biology, medicine, and chemistry. In terms of social sciences, its sphere is still yet to solidify.

In the next section, we will provide a summary of the Santa Fe Institute and its Economics Program which is considered to be where Complexity Economics had its start. This historical approach gives a perspective to the foundations of complexity economics, and how the field has been evolved over the years.

\section{Complexity economics: Santa Fe Institute, where it all started}

The history of complexity economics at SFI is elaborately explained by Fontana, through her interviews with SFI researchers [15]. SFI was founded in 1983 by the physicist George Cowan, who had worked on the Manhattan project. His aim was to start a research institute where researchers from various fields can collaborate for interdisciplinary, "blue-sky" research to connect "soft sciences" with "hard sciences". It should be noted that these were the times where systems studies were very popular, especially Kuhn's Structure of Scientific Revolutions [17], and the Club of Rome and their work "Limits to Growth" [18], [19].

Kuhn makes a distinction between "ordinary" and "extraordinary" science where he argues that ordinary science in a certain field inevitably faces a crisis due to the inadequacy of its paradigm. This crisis forces scientists to come up with a new paradigm. The effort in establishing the new paradigm is referred to as extraordinary science, after which, the new paradigm becomes the dominant paradigm and is used in subsequent scientific work. After the switch, subsequent scientific work, which follows the new paradigm, is once again considered as ordinary science. The switch is referred to as a "paradigm shift".

The Club of Rome with its work "Limits to Growth" written for the general public, considers five factors of the world (population, nonrenewable resources, industrial output, pollution, and agricultural production) and forecasts that the world cannot live beyond 2100. This study is based on "Systems Dynamics", a tool based on feedback loops developed in 1950's by J. Forrester, a professor from the MIT Business School with an electrical engineering background [20]. The study was well received by academia and the community, while its forecasts still seem to hold today [19].

Given these, Cowan's initiative might be akin to a certain trend in science that is a consequence of a crisis in both soft and hard sciences, prompting a search for a new paradigm. In this respect, economics was taken as a starting point. Economics is a good choice since, among all social sciences, it is the most prevalent applied science. Three workshops were organized throughout the years, in 1987, 1996, and 2001. Fontana describes these workshops as weakly heterodox, strongly heterodox, and synthesis, respectively. After each workshop, the participants published their discussions, and findings in the book series The Economy as an Evolving Complex System.

In 1987, ten physicists led by the Nobel Laureate Philip Anderson, and ten economists led by another Nobel Laureate Kenneth Arrow met for their first ten-day workshop. It should be noted that Anderson was known for his anti-reductionist views, and Arrow for his reductionist neoclassical approach. Fontana also defines neoclassical economics as "economic thought which relies on market equilibrium as its organizing concept" [15, p.168]. She acknowledges the change of neoclassical economics throughout the years, but states that this is how SFI used it initially, and it also underlines the core of "orthodox economic thinking". Arrow commented that the effort should not be considered as a fully new approach, and that it should be a part of general economics [21, p.280]. Some scholars [11], [22] had opposing views, and the workshop ended up drifting apart from the neoclassic tradition [15, p.170].

A year later, SFI started their Economic Program under the chair of the economist Brian Arthur, who also participated in the first workshop. He was the only economist at the workshop who is known for his heterodox approach in economics. With the contribution of Brian Arthur and John Holland, complexity economics took 
another path that deviates from traditional economics. Arthur stresses that stochastic dynamics, and increasing returns as well as its relevant notions of path dependence (non-ergodicity) and lock-in, are due to the fact that:

“...complex systems are systems with multiple elements adapting or reacting to the [aggregate] pattern. Through time via adjustment and change, as the elements react, the aggregate changes; as the aggregate changes, the elements change anew" [11, p.2].

Regarding conventional (traditional) economics, he also adds:

"Conventional economic theory chooses not to study the unfolding of the patterns its agents create, but rather to simplify its questions in order to seek analytical solutions" [23].

Thus, he differentiates complexity economics from traditional economics by stating that:

"Conventional economics studies consistent patterns in behavioral equilibrium, patterns that would induce no further reaction [whereas complexity economics seeks to understand] how actions, strategies, or expectations might react in general to -might endogenously change with- the aggregate patterns these create" [24].

During his position as the director of the Economics Program, Arthur and other SFI researchers developed popularized agent-based simulation to be used in complexity economics. Arthur introduced the El-Farol Bar problem and argued that agents' self-referential decision-making process is based on induction rather than deduction. Thus, he insisted on "plurality of views of cognitive foundation of economics, in opposition to the mainstream's monofoundation of deductive optimizing rationality." [15, p.178].

John Holland, on the other hand, brings attention to algorithm-based computer simulations instead of equation-based mathematics [25]. He calls complex systems as adaptive nonlinear networks (ANNs) and he proposes detailed properties of ANNs which are, "dispersed interaction, having no global controller, hierarchical organization, continuous adaptation, perpetual novelty, and non-equilibrium dynamics". This subject is relatively extensive with substantial work [15], [23], [25]. In his view, Holland suggests that ANNs do not assume the perfect knowledge or rationality. ANNs also enable heterogeneity for agents. He proposes Genetic Algorithms (GA) for economics models as he suggests that GA incorporates the properties of ANNs [15, p.175].

The second workshop in 1996 shows how much complexity economics drifted apart from mainstream economics. Fontana refers this period as "strongly heterodox". As such, the Santa Fe Perspective had become more centric to Holland's definition in 1988. ANNs had started to be referred as "complex adaptive systems". The workshop stood on two objectives: cognitive and structural foundations, for which SFI advocated a more pluralistic view rather than a one unified cognitive foundation in reasoning, due to the adaptation and interpretation properties of agents. The workshop gained a lot of popularity in the science world, and more and more researchers worked at the institute as it led complexity economics closer to mainstream economics. Under the directorship of Samuel Bowles in 2000-2003, the workshop in 2001 implied a merge between the Santa Fe Perspective and mainstream economics (the directors of the SFI Economics Program, and its themes throughout the years are provided by Fontana [15]).

\section{Complexity economics: Current debates}

One of the central debates is whether complexity economics subsumes economics, or vice versa. Fontana [26] argues that, in terms of Kuhn's idea of scientific revolutions, complexity economics is a new paradigm to mainstream economics and debates that ontologically the complexity economics view cannot be incorporated into economics. Many others ([4], [27], [28], [29]), especially from the SFI are in accord with this view. Arthur adds that:

"This shift - seeing the economy as an evolving, complex system - had three implications: 
1. Because it included heterogeneous agents (differing consumers, banks, firms) together creating the patterns they reacted to, models could not easily be "solved" analytically. The natural approach was agent-based modeling.

2. Because agents in most models attempted to formulate decisions in a problem where other agents (who differed in unknown ways) were trying to do the same, ill-defined decision problems resulted. Decision making in this context could best be seen as inductive, not deductive. Hence, we focused greatly on issues of cognition in the economy, making heavy use initially of John Holland's ideas.

3. Because agents reacted to the patterns, they are co-created, by definition the problems we investigated started out of equilibrium (i.e. not at a static solution point). The appropriate research question in each problem was what patterns or outcomes would arise? Would the system find its way to a conventional equilibrium? Or would it find ever-new patterns, and produce perpetual novelty?" [30].

Among SFI scholars, there are variants to the complexity economics approach that revolve around Arthur's ideas. Tuxford [14, p.252], recognizes them as generative economics [31]; interactive-agent economics [32]; agent-based computational economics [33]; and complex economics [34].

Arthur [37] calls these scholars as "optimists". Tuxford summarizes the optimists' main objection for the mainstream economics:

"....what these theorists are arguing for, is the rejection of mainstream methodological practice in favor of one that is essentially based on mechanisms; it is a rejection of descriptivist and instrumentalist practice focused on prediction, in favor of a realist alternative targeted at successful explanation." [14, p. 251].

UNPACKING OUR CURRENT IMAGINED ORDER

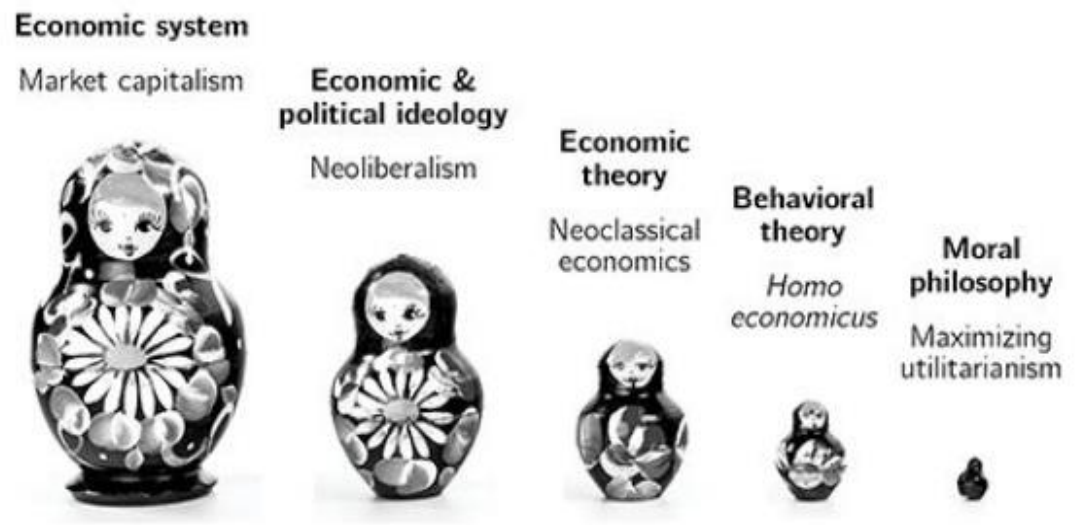

Figure 1. Beinhocker's imagined economic order [36]

Moreover, in his talk in the SFI 2019 Fall Symposium, the American economists and SFI Researcher, Beinhocker states that the economy is a human created imagined order which he visualizes as Russian matryoshka dolls (Figure 1) [36]. He argues that the today's economic system is based on homo economicus, referring to the assumption that human beings are selfish and pursue only their pleasures, or in other words, aim to maximize their utilities. He adds that this theory is proven to be not true and is part of an "armchair economy" - a term coined by Herbert Simon to indicate that the 18-19th century economists came up these theories without any scientific support, sitting in their armchairs. Beinhocker explains that today's science supports the idea that "real human decision-making is inductive and heuristic, modular, emotionally intelligent, and highly social." [36]. He concludes his speech by suggesting a new economic order (Figure 2) that is based upon current scientific ideas. 


\section{A NEW IMAGINED ORDER IS POSSIBLE}

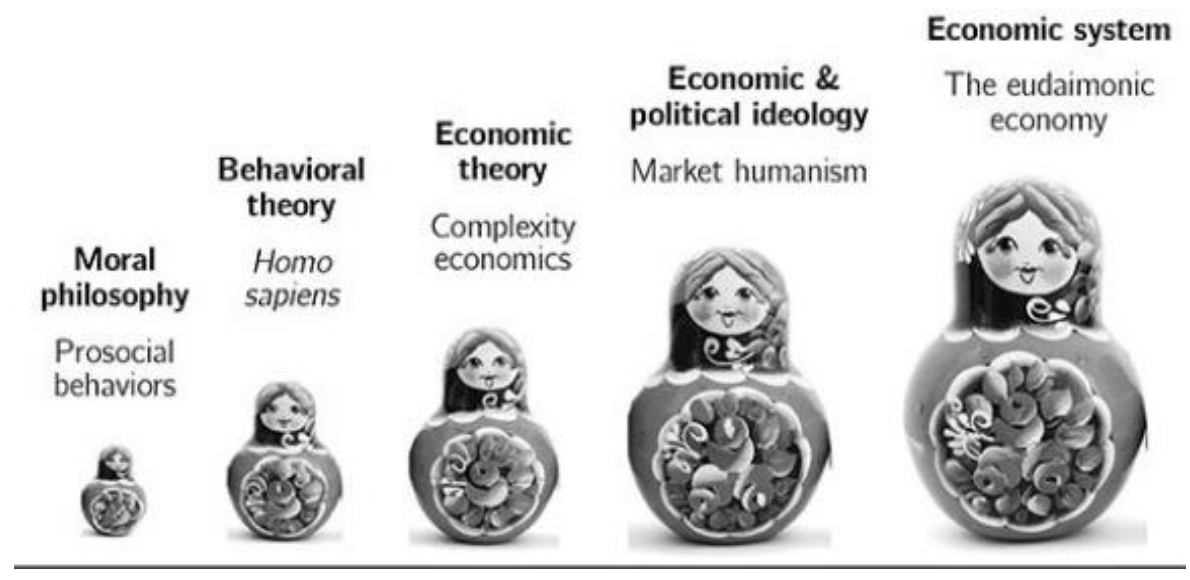

Figure 2. Beinhocker's suggested economic order [36]

SFI's perspective is an optimist one; however, in the spectrum of course, there are some scholars who are "less optimists". As we mentioned in the previous section, SFI had become more genial in recent years towards orthodox economics. According to the latest workshop that they held in 2019, there is a consensus that complexity economics is vital to solving current and future problems in and relevant to economy, and that the economists need to leave traditional approaches [37]. However, a "less optimist" SFI researcher Scott Page debates that equilibrium-based neoclassical economics and non-equilibrium-based complexity economics needs to be studied in a more complementary manner, rather than competing to be the dominant framework [38]. Grabner et al, [39] also provide a preliminary study to show how equilibrium-based models and agent-based simulation (nonequlibrium-based model) approaches together can give rise to insightful results. Their work tests their claims on the Kuznets hypothesis (long-run relationship between economic development and unemployment).

On the other side of the spectrum, there are "modest" scholars as in Schasfoort's expression. Modests oppose the optimists, arguing that mainstream economics subsumes complexity, and complexity economics is complementary to mainstream economics [40]. The term "modesty" is used by Hoogduin in his speech at the OECD in 2016. In his speech, Hoogduin stated that the economists should be "modest" in terms of what they can achieve in economy, and that we should accept that the future cannot be predicted [41, p.11]. He affirms that neo-Austrian and especially the Hayek tradition along with some cognitive sciences can be a solid foundation for complexity economics. Hoogduin's view is aligned with Montgomery [42] who compares complexity economics with the Hayek tradition.

Concurrent to the modest perspective, some scholars suggest that institutional economics and complexity economics complement each other [1], [43]. In his work, Grabner argues that institutional economics provides a meta-theoretical foundation that complexity economics lack, and complexity economics provide methods (such as agent-based simulation) to institutional economics. He also adds that institutionalists such as Veblen and Myrdal already studied economics as a complex system without specifically used the word "complexity" [1].

Another point he adds is that if complexity economics is to be studied, the focus should be on mechanisms with deep explanations. A mechanism in his definition, which is based on Bunge's definition [44], “... is a process or sequence of states in a concrete system" [1, p.398]. Deep explanations are the opposing view to Occam's razor, which states that if two theories explain the same phenomena, then the simplest one should be preferred. Grabner debates that not the simplest theory, but deeper theory that explains more underlying mechanisms in a phenomenon should be selected. Tuxford in his PhD thesis debates that the institutionalist methodology is not mechanistic and suggests a neo-mechanistic framework under complexity economics [14]. 
Using his neo-machanistic complexity economics framework, he shows that the asset pricing phenomena can be explained, whereas orthodox economics fails to do so.

Schasfoort [35] also reports on the current debates in the field. In addition to the debates between orthodoxheterodox economics, and optimist-modest economists, he also adds that there is a debate of how complex a model should be among complexity economists who use formal mathematical models; the lack of model description protocol in agent-based simulation; and how to validate agent-based simulation. However, these are rather discussions due to the fact that complexity economics is still an unsettled field. While we still cannot demarcate complexity economics per se, it is not unusual that its application and methods are still being debated.

\section{Conclusion and future study}

This document summarizes the work done to date in complexity economics. The topic is in the general domain of complexity theory and in the emerging field of complexity economics.

Concurrent with the discussions given in the previous section, future studies that aim to investigate whether complexity economics and mainstream economics can co-exist might yield a broader understanding. More specifically, non-equilibria are one of the salient features of complexity economics. However, mainstream economics that is seen to be equation-based, has already been well established, and consistently yields useful insights. So, when is it better to use an equation-based approach and when is it better to consider nonequilibria? Is it possible to build a framework in complexity economics making use of the equation-based neoclassical approach? This topic will not only provide a specific starting point, but also enjoys some of the most extensive body of literature in the field. Future work is necessary to fully establish whether complexity economics subsumes economics or vice versa, or perhaps something else.

With complexity economics becoming a trendsetter, the larger question regarding whether other disciplines that traditionally rely on concepts of optima, equilibria, and descriptive equations may also benefit from parallel studies that have a similar complexity perspective. Would a complexity framework be useful to applied fields such as artificial intelligence, service systems, Industrie 4.0, sustainability, or production systems? Are all engineering systems, when they reach a certain extend of activity, be best viewed as complex systems? What kind of contributions might a complexity framework bring to our current understanding and engineering know-how? These are the most fundamental future questions the formulation of whose answers may benefit from this brief review of complexity economics.

\section{References}

[1] C. Grabner, "The Complementary Relationship Between Institutional and Complexity Economics: The Example of Deep Mechanistic Explanations," Journal of Economic Issues, vol. 51, no. 2, pp. 392-400, 2017. doi: $10.1080 / 00213624.2017 .1320915$

[2] D. Colander, Editor, Complexity and the History of Economic Thought: Perspectives on the History of Economic Thought. Routledge, 2000.

[3] J. D. Farmer, "Economics needs to treat the economy as a complex system," In Paper for the INET Conference Rethinking Economics and Politics, Vol. 14, 2012.

[4] B. Arthur, "Complexity Economics: A different framework for economic thought," In Complexity and the Economics, Oxford University Press, 2015, pp. 1-30.

[5] J. Horgan, "From complexity to perplexity," Scientific American, vol. 272, no. 6, pp. 104-109, 1995.

[6] Bogdanov, Tektologiya, Vseobschaya Organizatsionnaya Nauka in 3 volumes, Berlin and PetrogradMoscow, 1922.

[7] W. Weaver, "Science and Complexity," American Scientist, vol. 36, no. 536, pp. 1-11, 1948. Available: https://doi.org/10.1201/9781315383132 
[8] M. Mitchell, Complexity: A Guided Tour. Oxford University Press, 2009.

[9] T. C. Schelling, Micromotives and macrobehavior. WW Norton \& Company, 1978.

[10] Y. Bar-Yam, Dynamics of complex systems, 1997. https://necsi.edu/dynamics-of-complex-systems

[11] B. Arthur, "Complexity and the Economy," Science, vol. 284, 1999.

[12] P. Anderson, K. Arrow, D. Pines (Eds) The Economy as an Evolving Complex System, Reading, Addison-Wesley, 1988.

[13] K. Arrow, "Beyond General Equilibrium," In Cowan, Pines and Meltzer (eds), Complexity Metaphors, Models, and Reality, Westview Press, pp. 451-455, 1999.

[14] M. Tuxford, "Mechanistic Complexity Economics: A Methodological Framework for Economic Science," Doctoral Thesis, Macquarie University, 2019.

[15] M. Fontana, "The Santa Fe Perspective on Economics: Emerging Patterns in the Science of Complexity," History of Economics Ideas, vol. 18, no. 2, pp. 167-196, 2010.

[16] B. Castellani, Map of the Complexity Sciences. Art \& Science Factory, 2018. https://www.artsciencefactory.com/complexity-map_feb09.html

[17] T. S. Kuhn, The structure of scientific revolutions. University of Chicago press, 1962.

[18] D. H. Meadows, D. L. Meadows, J. Randers, W. W. Behrens, The limits to growth. New York, 1972.

[19] D. Meadows, J. Randers, D. Meadows, Limits to growth: The 30-year update. Chelsea Green Publishing, 2004.

[20] J. W. Forrester, "System dynamics, systems thinking, and soft OR," System dynamics review, vol. 10, no. 23, pp. 245-256, 1994.

[21] K. Arrow, "Workshop on the Economy as an Evolving Complex System: Summary," In Anderson, Arrow, Pines (eds), The Economy as an Evolving Complex System, CRC Press, pp. 275-281, 1988.

[22] P. Anderson, “More is Different," Science, vol. 177, no. 4047, pp. 393-396, 1972.

[23] B. Arthur, S. N. Durlauf, D. Lane, "Introduction, Process and Emergence in the Economy," In Arthur, Durlauf, Lane (Eds), The Economy as an Evolving Complex Systems II, CRC Press, pp. 1-14, 1997.

[24] B. Arthur, "Self-Reinforcing Mechanism in Economics," In Anderson, Arrow, Pines (eds.), The Economy as an Evolving Complex System, CRC Press, pp. 9-28, 1988.

[25] J. Holland, "The global economy as an adaptive process," In Anderson, Arrow, Pines (eds.), The Economy as an Evolving Complex System, CRC Press, pp. 117-124, 1988.

[26] M. Fontana, The complexity approach to economics: A paradigm shift. Working paper no. 01/2018, CESMEP, Universita di Torino, 2008.

[27] D. Davis, "Is mainstream economics a science bubble?," Review of Political Economy, vol. 29, no. 4, 523-538, 2017. doi: 10.1080/09538259.2017.1388983

[28] W. Elsner, "Complexity Economics as heterodoxy: Theory and policy," Journal of Economic Issues, vol. 51, no. 4, pp. 939-978, 2017. doi: 10.1080/00213624.2017.1391570

[29] J. D. Farmer, D. Foley, “The economy needs agent-based modelling,” Nature, vol. 460, no. 6, pp. 685686, 2019.

[30] B. Arthur, Letter to Martin Shubik, in Shubik, pp. 11-12, 2003.

[31] J. Epstein, "Agent-Based Computational Models and Generative Social Science," Complexity, vol. 4, no. 5, pp.41-60, 1999.

[32] J. Miller, S. Page, Complex adaptive systems: An introduction to computational models of social life, Princeton University Press, 2007. 
[33] L. Tesfatsion, "Agent-based computational economics: Growing economies from the bottom up," Artificial Life, vol. 8, pp. 55-82, 2002.

[34] A. Kirman, Complex Economics: Individual and Collective Rationality, Routledge, 2011.

[35] J. Schasfoort, Complexity Economics, Exploring-economics.org, Sept 2017. https://www.exploringeconomics.org/en/orientation/complexity-economics/

[36] E. D., Beinhocker, "Can complexity economics save the world?," In Arthur, Beinhocker, Stanger (eds.), Complexity Economics, Dialogues of the Applied Complexity Network I, Proceedings of the Santa Fe Institute's 2019 Fall Symposium, SFI Press, pp. 33-53, 2020.

[37] B. Arthur, E. Beinhocker, A. Stanger, (Eds.) Complexity Economics, Dialogues of the Applied Complexity Network I, Proceedings of the Santa Fe Institute's 2019 Fall Symposium. SFI Press, 2020.

[38] S. Page, "The equilibrist and complexiologist can be friends," In Arthur, Beinhocker, Stanger (eds.), Complexity Economics, Dialogues of the Applied Complexity Network I, Proceedings of the Santa Fe Institute's 2019 Fall Symposium, SFI Press, pp. 243-253, 2020.

[39] C. Grabner, C. Bale, B. Furtado, B. Alvarez-Pereira, J. E. Gentile, H. Henderson, F. Lipari, "Getting the best of the worlds? Developing Complementary Equation-Based and Agent-Based Models," Computational Economics, vol. 53, no. 2, pp. 763-782, 2019.

[40] S. N. Durlauf, "Complexity, economics, and public policy," Politics, Philosophy \& Economics, vol. 11, no. 1, pp. 45-75, 2012. https://doi.org/10.1177/1470594X11434625

[41] L. Hoogduin, "Complexity, modesty, and economic policy," New Approaches to Economic Challenges: Insights into Complexity and Policy, OECD, Institute for New Economic Thinking, Sept. 2016, pp. 11-13.

[42] M. Montgomery, "Complexity theory: An Austrian perspective," In Colander, D. (Ed), Complexity and the History of Economic Thought: Perspectives on the History of Economic Thought, Routledge, pp. 227-241, 2000.

[43] R. E. Prasch, "Complexity and economic method: An Institutional perspective," In Colander, D. (Ed), Complexity and the History of Economic Thought: Perspectives on the History of Economic Thought, Routledge, pp.215-227, 2000.

[43] M. Bunge, "How does it work: The search for explanatory mechanisms," Philosophy of the Social Sciences, vol 34, no. 2, pp. 182-210, 2004. 